\title{
Norois
}

Environnement, aménagement, société

\section{Marie REDON, Géopolitique des îles}

\section{Antonin Margier}

\section{OpenEdition \\ Journals}

Édition électronique

URL : https://journals.openedition.org/norois/11275

DOI : $10.4000 /$ norois. 11275

ISSN : $1760-8546$

\section{Éditeur}

Presses universitaires de Rennes

\section{Édition imprimée}

Date de publication : 15 décembre 2021

Pagination : 257-258

ISBN : 978-2-7535-8588-1

ISSN : 0029-182X

\section{Référence électronique}

Antonin Margier, « Marie REDon, Géopolitique des îles », Norois [En ligne], 259-260 | 2021, mis en ligne le 15 décembre 2021, consulté le 25 octobre 2022. URL : http://journals.openedition.org/norois/11275 ; DOI : https://doi.org/10.4000/norois. 11275 

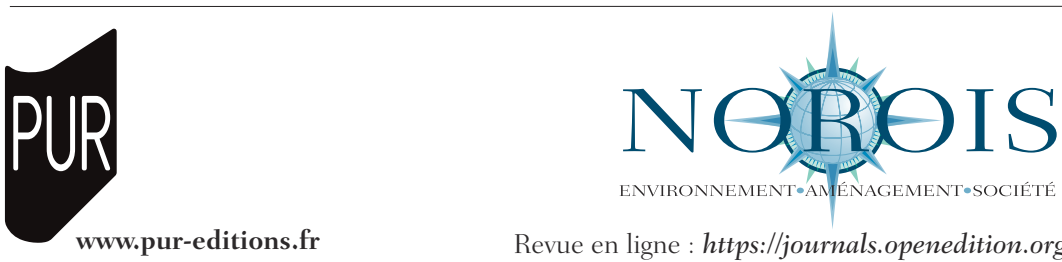

Revue en ligne : https://journals.openedition.org/norois/

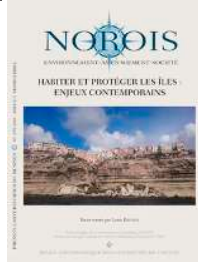

\section{COMPTE RENDU BIBLIOGRAPHIQUE}

Redon Marie, Géopolitique des îles, Paris, Le Cavalier Bleu, 2019, 174 p.

Symboliquement associées à des espaces isolés, tropicaux et paradisiaques, les îles sont bien plus diverses et complexes que ne le laisse supposer cette représentation commune. Non seulement les territoires insulaires sont extrêmement variés il n'est que de penser au Mont-Saint-Michel, à la Grande-Bretagne ou à Cuba et Tahiti - mais ils sont aujourd'hui pleinement inscrits dans la mondialisation. À travers cet ouvrage synthétique, Marie Redon propose justement de déconstruire les visions idéalisées, et parfois figées, des îles pour en dévoiler toute la complexité et mettre en lumière la façon dont elles se transforment dans un contexte d'hypermobilité.

Longtemps éloignées dans les confins maritimes et préservées des remous du monde, c'est à partir du $15^{\mathrm{e}}$ siècle que les îles acquièrent progressivement une place dans l'histoire de la mondialisation en tant qu'étapes sur les routes maritimes qui se développent alors en lien avec la conquête européenne du globe. Représentant souvent le dernier point de ravitaillement avant la traversée des océans, certaines îles ont en effet pris une importance conséquente dans ce processus. Mais au-delà de simples relais de l'expansion territoriale, ces îles ont progressivement acquis une importance géopolitique dans la concurrence entre les pays européens, menant à d'importantes réflexions sur le statut de ces territoires et des ressources aquatiques qui y sont associées. L'auteure retrace finement toutes les réflexions menées par les spécialistes au cours des derniers siècles pour donner un statut juridique

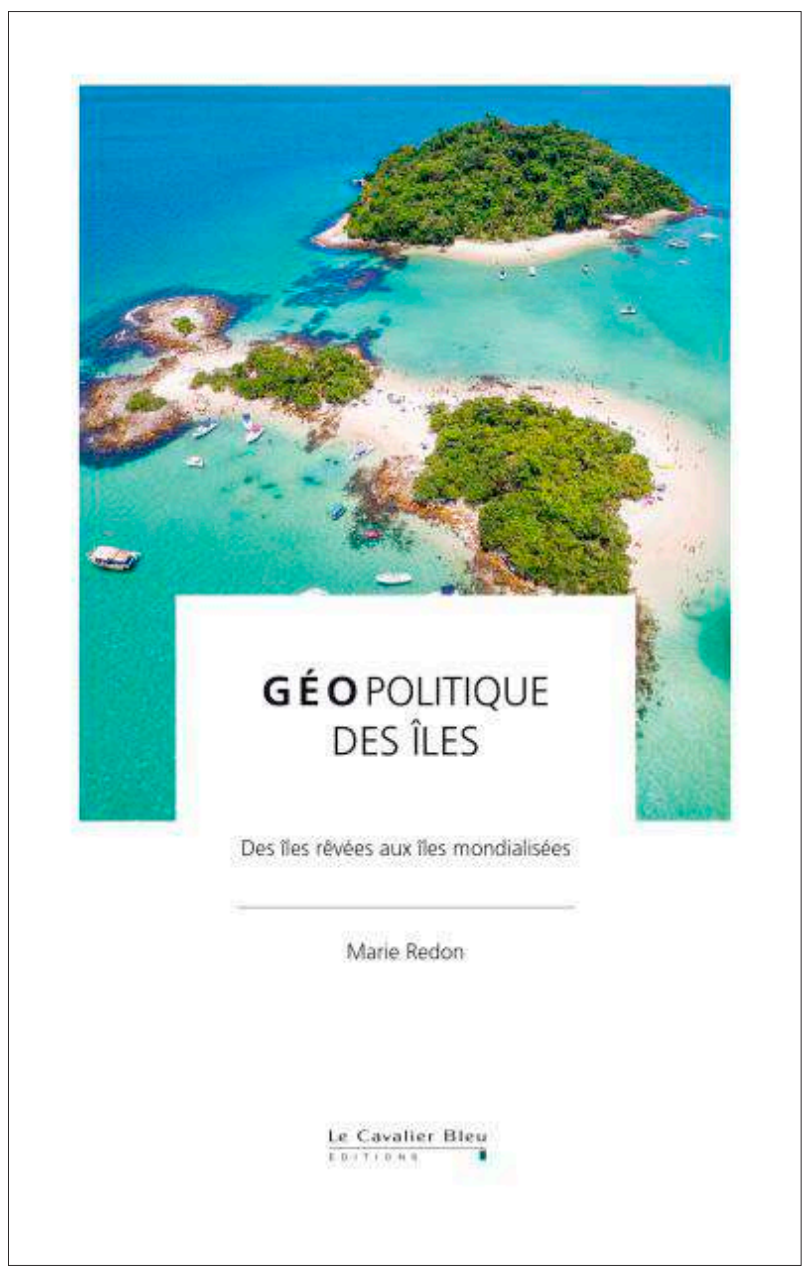

aux eaux maritimes. Après le partage des territoires qui a marqué le monde des $19^{\mathrm{e}}$ et $20^{\mathrm{e}}$ siècles, nous serions entrés depuis les années 1980 dans 
une « ère de partage des espaces maritimes » qui ne fait que s'intensifier. La délimitation des zones économiques exclusives (ZEE), qui attribuent des droits économiques sur 200 miles nautiques, a redonné évidemment une importance particulière aux îles, (ré)activant des rivalités territoriales et politiques à propos de certaines micro-îles perdues aux confins des océans mais dorénavant devenues des ressources stratégiques majeures et de potentiels leviers d'expansion « merritoriale».

Les îles apparaissent donc prises au sein d'importantes dynamiques géopolitiques, économiques et culturelles qui les dépassent. Comme le dit l'auteure, "les îles ne sont jamais vraiment en têteà-tête avec elles-mêmes mais incluses dans des logiques économiques mouvantes et globales ». Le tourisme de masse est évidemment un des exemples les plus emblématiques de cette intégration dans la globalisation, $10 \%$ de la fréquentation touristique internationale concernant aujourd'hui les destinations insulaires, avec des effets ambivalents de développement territorial et de dégradation des écosystèmes locaux. Un autre exemple symptomatique de la façon dont les îles sont en prise avec l'actualité est celui des migrations dites "irrégulières ». Les îles méditerranéennes, qui constituent souvent des points d'entrées en Europe, occupent en effet une place importante dans les parcours migratoires. Dans un contexte d'attractivité de l'Europe, certaines îles peuvent concentrer des flux extrêmement difficiles à gérer au quotidien, à l'instar de Lampedusa où plus de 50000 migrants sont arrivés en 2011. L'auteur évoque également le cas de Mayotte, devenue département français en 2011 , que des dizaines de comoriens tentent de rejoindre chaque jour. Lî̀le est aujourd'hui composée à $45 \%$ de personnes étrangères en situation irrégulière avec 20000 reconduites par an à la frontière, sur les îles voisines. Du fait de cette localisation en périphérie de l'espace Schengen, il est souvent exigé de ces îles qu'elles filtrent et régulent ces arrivées illégales, ce que l'auteure appelle la «frontiérisation » des îles.
«Loin d'être à l'écart des dynamiques du monde contemporain, d'être des lieux périphériques, marginaux », les îles constituent donc des « enclaves paradoxales » à la fois isolées et connectées. C'est notamment cette spécificité des territoires insulaires, entre ouverture et fermeture, qui leur donnent « un rôle central dans [la] circulation globalisée, à la fois dans son versant légal comme dans son versant illégal ». En effet, la plupart des États désignés comme "paradis fiscaux » par l'OCDE s'avèrent être des îles dans lesquelles certaines spécificités (taxations insignifiantes, opacité sur le régime fiscal, absence d'échange de renseignements fiscaux) permettent d'attirer des capitaux. La flexibilité des réglementations de certains territoires insulaires permet en outre que se développe dans les «interstices de la légalité » toute une économie du jeu. Par ailleurs, du fait d'une localisation éloignée et d'une histoire ayant fait de ces îles des espaces peu surveillés, certaines îles se sont progressivement inscrites sur les routes du trafic de drogue. L'auteure nous apprend notamment que $40 \%$ des quantités de drogue qui remontent des pays producteurs vers le marché américain transitent par la voie insulaire dans la région des Caraïbes, participant ainsi à une recomposition majeure du fonctionnement des îles concernées.

Ainsi, cet ouvrage constitue un état des lieux stimulant sur les îles contemporaines et met en lumière la diversité des situations et la nécessité d'éviter toute généralisation à leur propos. À travers la mobilisation d'un vaste ensemble de ressources théoriques et empiriques, Marie Redon donne à lire un panorama large et diversifié des enjeux actuels des espaces insulaires. Envers de la clarté synthétique du propos et des thématiques abordées, il est parfois regrettable que certaines ne soient qu'effleurées, mais libre alors aux lecteurs de suivre les références bibliographiques pour aller plus loin.

Antonin Margier Université de Rennes 2 